\title{
ACERCA DE LAS CONSECUENCIAS SOCIALES DE LA ARQUEOLOGÍA. EPISTEMOLOGÍA Y POLÍTICA DE LA PRÁCTICA
}

\author{
Rafael Pedro Curtoni \\ INCUAPA, Facultad de Ciencias Sociales.UNCPBA, Avda. del Valle 5737 \\ Email:rcurtoni@soc.unicen.edu.ar
}

Presentado: 31/03/08 - Aceptado: 4/09/08

\begin{abstract}
Resumen
En este trabajo se discute acerca de las consecuencias sociales de la arqueología considerando que buena parte de la misma funciona de acuerdo a los principios y postulados de la ciencia moderna occidental. Consideramos que esos mandatos constituyen una contradicción y un obstáculo para el involucramiento social dado que prescriben un deber ser sustentado en la neutralidad valorativa y la asepsia epistemológica. Como contrapartida, se propone considerar epistemología y política en conjunto como ámbito de oportunidades teniendo en cuenta las localizaciones geopolíticas de producción de los saberes.
\end{abstract}

Palabras clave: Arqueología, Epistemología, Política.

\begin{abstract}
In this paper the social involvements of archeology are discussed regarding that almost all of the discipline functions following the principles and paradigms of the western modern science. We regard that these principles constitutes a type of contradiction and a obstacle to the social involvement as they prescribe a way ofbeing that is supported by neutrality and epistemological freedom. On the contrary, it is proposed to consider epistemology and politics as a whole and as arena of opportunities accounting the geopolitics of knowledge production.
\end{abstract}

Keywords: Archaeology, Epistemology, Polítics.

\section{Introducción}

Desde hace ya algunos años se acepta el presupuesto general que la arqueología, en tanto disciplina que se desarrolla en un contexto social determinado, tiene inevitablemente, consecuencias sociales y políticas. En las últimas décadas y en diferentes países sudamericanos ello se ha expresado en relación con los distintos grupos subalternizados (por medio de la visibilización y participación en la investigación), y en vinculación con los casos de terrorismo de estado (Ayala et al. 2003, Funari y Zarankin 2006, Green et al. 2003, Gnecco y Piazzini 2003, Lima 2003, Nielsen et al. 2003, Politis 2001). En nuestro país, sostener y repetir este presupuesto sin mayores especificaciones implica, para muchos, casi una obviedad, algo inevitable y sin cuestionamientos, en fin, una certeza consumada. Considerar a este supuesto como algo intrínseco a la disciplina, como ya dado e insoslayable a la praxis arqueológica no ha hecho otra cosa que naturalizar y esencializar su sentido. Esta naturalización ha sido y es un 
poderoso y eficaz mecanismo generado en el interior mismo del modernismo y aún de las tendencias postmodernas que tiende precisamente a neutralizar los efectos de la propia propuesta superadora. Por eso, la apostilla que sostiene que "la arqueología tiene consecuencias sociales" se ha convertido en un enunciado discursivo (en términos de Foucault) irreductible, esencial y exteriorizado. Asimismo, todo discurso manifiesto reposa sobre algo "no dicho" y a su vez puede llegar a excluir otras formas de enunciación como los saberes locales y/o indígenas. Lo "no dicho", en el enunciado "la arqueología tiene consecuencias sociales", puede vincularse con derivaciones que busquen establecer límites y formas precautorias dela praxis (e.g. criterios de autenticidad, legitimidad, verdad). La definición y puesta en escena de esas formas del hacer, de los límites disciplinarios, de la agenda, se relacionan con una serie de dispositivos históricos (e.g. discursivos, institucionales, reglamentarios), que preestablecen diversos modos de sujeción por medio de los cuales nos asumimos como sujetos morales (ontología ética), en sujetos de un cierto saber (ontología de la verdad) y como sujetos que actuamos sobre los demás (ontología de poder). En ese sentido, la arqueología como disciplina puede ser caracterizada como una formación discursiva (sensu Foucault 1997), donde tanto lo dicho como lo no dicho funcionan como un conjunto de reglas, enunciados y relaciones que prescriben la regularidad de la práctica y un "deber ser". En la arqueología argentina y con excepción de contados casos, la tendencia general acerca de la aceptacion de las consecuencias sociales de la práctica no ha podido trascender la instancia meramente declarativa y no ha generado, por tanto, un impacto concreto en situaciones específicas.

De esta manera, el objetivo de este trabajo es analizar las implicancias de la aceptación de las consecuencias sociales de la arqueología de nuestro país en los últimos años. El reflejo de este aspecto de la práctica se discutirá basicamente considerando la apertura académica y las relaciones establecidas con las comunidades locales. Entre las situaciones contemporáneas que interpelan el rol social de la arqueología se encuentran, por un lado, los continuos procesos de despojos de campesinos e indígenas de sus tierras y por otro, la participación de los mismos en proyectos de investigación. Sostenemos que los principios y postulados de la ciencia moderna occidental, suscriptos por buena parte de la arqueología en Argentina, constituyen una contradicción y un obstáculo para el involucramiento social y político de la misma, dado que prescriben un deber ser sustentado en la neutralidad valorativa y la asepsia epistemológica. Como alternativa, se propone considerar la práctica de la disciplina a la luz de la conjunción de epistemología y política como ámbito de promoción de oportunidades situadas, críticas, transversales y múltiples. Ello implica una reconfiguración de la práctica cuyo punto de partida podría comenzar con planteos concretos de decolonización de la misma.

\section{Tierras, despojos y "Areas de estudio"}

En las últimas décadas las fronteras agrícolas de nuestro país se han expandido hasta límites insospechados, incorporándose de esa forma nuevas y extensas regiones antes consideradas "marginales" e "improductivas". Esta situación ha provocado el inicio de nuevos procesos de conquista de grandes extensiones de tierras por parte de megaproductores, consorcios agropecuarios y pool de empresas (Torterolo 2005). En la mayoría de los casos, el mecanismo utilizado para hacer efectiva la incorporación de tierras en el menor plazo se apoya en una despediada e intempestiva deforestación de bosques nativos. Estas acciones no solo generan importantes impactos ecológicos en amplios ecosistemas sino también diversidad de conflictos con los pobladores campesinos por el derecho de permanencia y posesión de los mismos en esos paisajes otrora considerados "marginales". 
Por ejemplo, en Santiago del Estero, desde hace años, numerosas familias campesinas son constante y brutalmente reprimidas por fuerzas policiales y parapoliciales para apropiarse de sus tierras (Dargoltz 1980, Dargoltz et al. 2005). El desmedido avance del desmonte ante la actual soja-manía arrasa con los puestos de los pobladores del monte, sus animales, pertenencias y con el derecho constitucional de posesión veinteañal fomentada desde el Estado (Art. 4015/16 del Código Civil y Art.75, inciso 17, de la Constitución Nacional Argentina).

Sumado a ello, últimamente también se han activado nuevos emprendimientos mineros y turísticos de distintas multinacionales que están expandiéndose en forma acelerada por todo el territorio nacional e impactando sobre espacios sociales y arqueológicos (Gómez Otero et al. 2007, Lema 2007, Miotti y Carden 2006, Revuelta 2007). En la localidad de Villa la Angostura, provincia de Neuquén, la comunidad mapuche Paichil Antriao denunció agresiones y amenazas de empresarios inmobiliarios vinculados al turismo que tratan de vender a manos privadas las tierras que tradicionalmente ocupan. La destrucción intencional de una ruka (casa) de la comunidad y el cercamiento perimetral de la tierra constituyen acciones violentas y autoritarias generadas con el consentimiento de algunos funcionarios locales (Diario Río Negro 2006, Curtoni y Chaparro 2007). Por otro lado, en años anteriores los mapuches reunidos en un parlamento regional denunciaron que la empresa Inversiones Mineras Argentinas (IMA Exploration Inc.) había profanado un cementerio de la comunidad localizado en proximidades del Camino del Buey, cerca de la localidad de Gastre, provincia de Chubut. La usurpación del lugar para realizar exploraciones mineras y el levantamiento de los restos humanos se habría realizado sin la autorización ni el consentimiento de la comunidad indígena local. Sin embargo y según la denuncia del parlamento regional, la empresa IMA habría actuado bajo el asesoramiento y resguardo de antropólogos profesionales quienes con "el escudo de la ciencia" levantaron los restos de los antepasados de la comunidad (Diario Río Negro 2005, Gómez Otero et al. 2007). En la denuncia efectuada los indígenas sostienen que el lugar donde se encuentran los entierros es considerado parte "del patrimonio histórico y cultural del pueblo-nación mapuche y no le pertenece ni a una empresa, ni a científicos sociales, ni a ningún museo" (Diario Río Negro, 2005).

La región pampeana no ha permanecido exenta a estos procesos y en la actualidad diferentes problemas afectan a buena parte de los "puesteros" del oeste pampeano (Comerci 2004). Estas tierras, históricamente relegadas y consideradas semidesérticas, han adquirido últimamente una nueva valoración económica y política. El cambio de percepción social experimentado implicó un viraje de "áreas marginales" a "zonas productivas" y conllevó también la aparición de nuevos agentes y productores con otras formas de considerar y visualizar el espacio. En los últimos años se han producido intentos de despojo y expulsión de los pobladores campesinos de sus tierras apelando a diferentes artilugios legales, utilizando el amedrentamiento y en algunos casos la violencia física. Estas situaciones se producen a pesar de la existencia de la ley de posesión veinteañal que otorga el derecho de propiedad de la tierra a aquellos pobladores que hayan permanecido por más de veinte años en el lugar y logrado el sustento familiar por medio de la misma (Curtoni et al. 2007). La mayor parte de los campesinos del oeste pampeano han vivido en esas tierras durante generaciones y nunca antes habían enfrentado amenazas tan graves al sentido de pertenencia al lugar que los identifica. Ante esta situación, hacia fines de 2006 se conformó en la provincia de La Pampa un Movimiento de Apoyo a la Lucha por la Tierra (MALUT), integrado por docentes, estudiantes, investigadores independientes, profesionales, organizaciones 
políticas, sociales y ambientalistas, con el objetivo de apoyar en diferentes instancias los reclamos efectuados por los pobladores del oeste pampeano.

Recientemente también se hicieron sentir las voces de algunas organizaciones mapuches de la provincia de Río Negro y de representantes Rankülches de La Pampa debido al hallazgo y exhumación de restos humanos realizado en la localidad de 25 de Mayo, provincia de La Pampa (Diario La Arena, 2007). Ambos grupos reclaman el cumplimiento de normativas y acuerdos previamente definidos que establecen la obligación para los investigadores de consultar y acordar con las comunidades locales las formas, permisos y características de los estudios a realizar. Diferentes cartas de intención y acuerdos realizados en congresos de la especialidad así como leyes nacionales e internacionales específicas preestablecen el necesario consentimiento de los pueblos originarios para la realización de investigaciones que involucren su patrimonio (e.g. Declaración de Río Cuarto 2005, Belli y Slavutsky 2005b, Endere 2002).

Todos estos procesos y fenómenos no solo están impactando negativamente en las formas de vida de los diferentes pobladores campesinos e indígenas de las distintas regiones, sino también, están poniendo en cuestión el rol de la ciencia y los profesionales frente a los mismos. Sobretodo considerando las exigencias de participación que efectuan los pueblos originarios en relación a temas de sus intereses y teniendo en cuenta que los despojos de tierras pueden ocurrir en "paisajes" que hayan sido elegidos como áreas de investigación arqueológica. Esta situación expresa, en general, cierta tensión al interior de las ciencias sociales entre aquellos que postulan un necesario involucramiento con los actores y problemas cotidianos y los que mantienen distancia académica. Para el caso de la arqueología de nuestro país se podría sostener que aún no ha madurado plenamente al interior de la disciplina la aceptación de su dimensión política y/o de las consecuencias sociales de su práctica.

\section{Arqueología, práctica y "otredad"}

En Argentina los casos de participación e involucramiento de actores locales extra académicos (indígenas y/o campesinos) en proyectos arqueológicos no han sido muy numerosos en la historia de la disciplina. En la actual década pareciera que esta tendencia esta revirtiéndose sobre todo debido a la mayor presencia de casos y arqueólogos preocupados por sus relaciones con las comunidades de referencia. Sin embargo, considerando los proyectos de largo alcance, el planteo de apertura de la arqueología y la participación efectiva de actores extra académicos en la investigación, parecen ser la excepción antes que la regla en nuestro país (Curtoni y Endere 2003, Miotti y Carden 2006). Un racconto somero de los mismos permitirá vislumbrar las diferentes formas y características que se fueron desarrollando entre los arqueólogos y representantes de las comunidades locales. Entre los primeros proyectos se encuentra el "programa de estudios arqueológicos del departamento San Carlos" (provincia de Salta), cuyo objetivo principal estaba orientado a conocer la tecnología agrícola prehispánica y aplicarla en combinación con la desarrollada por la comunidad local. Estas propuestas se realizaron a la luz de considerar a la arqueología como una disciplina aplicada que puede ser útil en ámbitos externos a la misma (Laguens y Bonnin 1985). Otro antecedente de importancia lo constituye la planificación y ejecución del Museo de sitio de Añelo, formado en 1989 en la provincia del Neuquén, y donde se exhibe un cementerio de cazadores recolectores de 500 años de antigüedad. Algunos integrantes de la comunidad Mapuche Paynemil participaron en las distintas etapas de la investigación del 
cementerio y en la actualidad son quienes custodian y administran el museo (Biset 1989, Cúneo 2004, Font et al. 1997).

Hacia fines de la década de 1980 y comienzos de la siguiente se generan en la provincia de Catamarca dos proyectos arqueológicos de relevancia que desde sus inicios plantearon y promovieron diferentes relaciones con las comunidades locales. Estas relaciones, generadas por distintos intereses, se mantuvieron, según sus impulsores, de manera continua hasta la actualidad. En el primer caso se trata del Proyecto Arqueológico Antofalla, de la Universidad Nacional de Catamarca e iniciado en 1989, el cual ha buscado incorporar integrantes de la comunidad indígena para definir, a partir de intereses comunitarios, prioridades y objetivos de la investigación (Haber et al. 2006). El sentido general de la práctica arqueológica parece sustentarse en la mutua interrelación y aprendizaje entre los investigadores y los integrantes de la comunidad, lo cual ha permitido promover acciones transformadoras y relevantes a nivel local y regional (Haber et al. 2006).

Unos años después, hacia 1992, se inician programas de auto-desarrollo local en la comunidad de Laguna Blanca, ubicada en la puna catamarqueña en el Noroeste argentino, impulsando proyectos de manejo y desarrollo turístico a partir de la puesta en valor de sitios arqueológicos y a la luz de una arqueología socialmente útil (sensu Delfino y Rodriguez 1992). En este sentido se han generado un conjunto de experiencias con actores locales como la reactivación de tecnologías agrícolas prehispánicas, la definición de un plan de manejo urbanístico ambiental, la utilización y desarrollo de energías alternativas, la participación comunitaria en la regulación dominial de tierras a favor de los pobladores de Laguna Blanca y la conformación del Museo Integral de la Reserva de Biosfera (Delfino et al. 2006).

En la Patagonia Argentina el Programa de Recursos Culturales, dependiente de la Administración de Parques Nacionales, impulsó la participación de grupos indígenas en las discusiones y decisiones relativas al manejo y puesta en valor del patrimonio. Como resultado de ese proceso se logró la restitución por parte de Parques Nacionales de un territorio de 341 hectáreas donde se encontraban lugares y elementos considerados sagrados para la comunidad Mapuche de Ñorquinco (Molinari 2000). Este caso significó un precedente importante para otras comunidades originarias que empezaron a plantear estrategias para la restitución de tierras ancestrales.

En los últimos años se han incrementado los trabajos y proyectos con el involucramiento y participación de representantes de las comunidades locales sobre todo para la discusión, planteo y puesta en valor de planes de manejo de los recursos culturales generalmente asociados con políticas de promoción turística, desarrollo local y difusión de las investigaciones (Aschero et al. 2003, Berón y Guastavino 2007, Callegari 2007, Granizo 2007, Iriarte y Werber 2003, Marchegiani et al. 2006, Montenegro y Cremonte 2007, Palma et al. 2007, Vitry y Soria 2006, Zaburlin et al. 2006). En algunos casos se han hecho sentir voces locales en disidencia por la patrimonialización de sus paisajes y por el sometimiento a las políticas de mercantilización, tal como ha sido planteado y discutido para la Quebrada de Humahuaca (Belli y Slavutsky 2005a y b, Endere 2005, Haber 2005). Entre estos proyectos se destaca la realización de una forma de práctica arqueológica "cotidiana" y en "armonía con el entorno social", el cual es el que otorga significados al patrimonio cultural, y desarrollada bajo las premisas de la consulta, el diálogo, el respeto y la participación comunitaria (Mamaní 2006: 94). Esta forma de considerar la arqueología tiene por objetivo accionar desde adentro 
y con la gente como protagonista principal para promover acciones concretas que tiendan a fortalecer el proceso de indentidad de las poblaciones andinas originarias (Mamaní 2006).

En síntesis, la aceptación de "las consecuencias sociales de la arqueología" ha derivado en diversas reacciones que se podrían agrupar en diferentes modalidades. Algunas de ellas estuvieron y están orientadas a desacralizar y/o deconstruir relaciones de poder, legitimaciones y principios de autoridad generados desde la disciplina y que han contribuido a establecer un distanciamiento cada vez mayor con aquello considerado como la "otredad". La consecuencia de ello ha sido la inclusión en los proyectos de investigación de actores locales, la promoción y resolución de intereses comunitarios, la búsqueda de "emancipación" de grupos subalternizados y la discusión sobre reclamos territoriales y/o patrimoniales (Laguens y Bonnin 1985, Biset 1989, Belli y Slavutsky 2005a, Haber 2006, Haber et al. 2006, Delfino et al. 2006, Mamaní 2006, Endere y Curtoni 2003, 2006, Gómez Otero et al. 2007). Estas aproximaciones plantean la necesaria integración e involucramiento de los grupos locales en las diferentes etapas de la investigación para planificar, decidir y actuar enfatizando a su vez el aprendizaje mutuo y transversal. Otras modalidades se relacionan con aquellos proyectos que promueven la participación comunitaria para el desarrollo sostenible generalmente asociado al turismo y puesta en valor del patrimonio cultural tangible e intangible (Callegari 2006, Granizo 2007, Iriarte y Werber 2003). Por último, algunas formas de trabajo se vinculan con las acciones de transferencia de los resultados de las investigaciones arqueológicas a la comunidad local para impulsar la preservación integral del patrimonio y el fortalecimiento de la identidad de la arqueología (Aschero et al. 2003, Montenegro y Cremonte 2007, Palma et al. 2007). En algunos casos estos proyectos plantean no sólo compartir la información arqueológica con la comunidad sino también fomentan una construcción del conocimiento sobre el pasado en la cual los actores locales participen activamente con sus saberes en la conformación del mismo (Castro et al. 2007, Seldes et al. 2006). Si bien se pueden identificar distintas modalidades de expresión de la apertura disciplinaria a través de las vinculaciones e involucramientos con los sujetos locales es necesario aclarar que estas no representan formas cerradas y excluyentes. Por el contrario, estas formas de considerar la práctica de la arqueología conforman trayectorias complejas, dinámicas y abiertas caracterizándose por la interrelación y las posibilidades de continuos cambios y reajustes. De esta forma, la participación no puede concebirse como un objetivo que será alcanzado plenamente y de manera satisfactoria y definitiva, sino como un itinerario multidireccional, multicausal, flexible y siempre en acción (Endere y Curtoni 2003).

En general, en las diversas formas de considerar la inclusión de los "otros", como parte de la aceptación de las consecuencias sociales de la arqueología, se mantiene (conciente o inconcientemente) el presupuesto de pre-existencia de al menos dos ámbitos del conocimiento distintos, uno vinculado con el saber científico y otro asociado con formas no sistemáticas del conocer. Gissli Pálsson identificó al conocimiento científico con los "expertos" y al saber popular con los "legos" (Pálsson, 2001). Los representantes del saber experto suelen aparecer y/o presentarse en esta retórica como los principales responsables de la apertura de la disciplina para la inclusión de los otros. Lo "no dicho" en esta retórica refiere a la esencia trascendental del enunciado discursivo que desnuda relaciones de dominación, poder y control que atraviesan la práctica arqueológica (expresado en los criterios científicos de autenticidad, legitimidad, verdad y empoderamiento). Por el contrario, en nuestro país se puede sostener que en la mayoría de los casos la apertura disciplinaria se ha generado a partir de intereses y pedidos concretos de las comunidades locales y no como pretende 
afirmar la lógica del poder discursivo (Marchegiani et al. 2006, Zaburlin et al. 2006). Por otra parte, la existencia de una brecha entre los "expertos" y los "legos" se reafirma y expresa, por ejemplo, a través de las pretensiones de empoderamiento. En la actitud de empoderar al otro subyace un sentido paternalista que busca posicionar y "proteger" al empoderado, reconociendo en ello incapacidad y/o limitaciones propias. Asimismo, empoderar resalta una visión clasista pues el que empodera detenta el saber/poder, contribuye al distanciamiento vertical y a fortalecer la figura del individuo o en términos de Vattimo (1989) del sujeto creador/fundador.

En otras palabras, después de varios años, publicaciones y congresos de rasgarnos las vestiduras sobre las consecuencias sociales de la disciplina y sobre la participación de los "otros" en la investigación, seguimos no en el mismo punto de partida pero sí en la misma senda. Es decir, buena parte de la arqueología argentina, con excepción de algunos logros y trabajos generados con los "otros" (lo cual ha permitido alejarse del punto de partida), permanece en una dirección en la cual mantiene y reproduce, bajo diferentes formas e intensidades, la retórica anterior. Ello se expresa en la tendencia positivista de la arqueología que es dominante en nuestro país y en la ausencia de interés e involucramiento con los temas y problemas de las comunidades originarias y/o campesinas. También se refleja por medio del mantenimiento del control discursivo (oral, textual y locus enunciativo) de la arqueología, lo cual sustenta la creencia en la preemiencia del conocimiento arqueológico como producto del saber científico por sobre otras formas diferentes del hacer y del conocer como las denominadas epistemologías "otras". Además, una consecuencia de lo anterior es la escasa presencia y representación de voces extra-académicas, como las indígenas y campesinas, tanto en la textualidad arqueológica como en los ámbitos de discusión específicos (e.g. congresos, jornadas, encuentros). En este sentido, la trayectoria de esta tendencia no impondrá por propio peso una radical re-conceptualización de la práctica disciplinaria porque la misma permanece orientada bajo principios y cánones positivos que preestablecen distanciamientos, asepsia y exclusividad de nexo entre arqueología y pasado. De esta manera, si quisiéramos representar el estado actual de la arqueología en nuestro país a la luz de las implicaciones sociales de la misma y apelando a una vieja metáfora, podríamos sostener que estamos aún en la edad de la inocencia. Los intentos por superar ese estado han sido diversos, desde algunas de las diferentes modalidades de inclusión y participación mencionadas, las alternativas multiculturales hasta las pretensiones de empoderamiento de los otros. Lo remarcable es que buena parte de estos intentos superadores han sido promovidos manteniendo un ideal de disciplina concebida bajo los principios teóricos y epistemológicos de la ciencia moderna occidental. Estimamos que esta forma de considerar la arqueología es uno de los mayores obstáculos que impide superar las contradicciones entre lo que se hace y aquello que se pretende hacer socialmente, disonancia que atenta contra la pérdida de inocencia y reafirma la neutralidad valorativa y el discurso monotópico.

\section{Epistemología, política y diferencia}

En el contexto actual, se podría sostener que buena parte de la arqueología argentina se encuentra presa de los sentidos de 'colonialidad del poder' y 'colonialidad del saber' que atraviesan tanto sus prácticas como sus discursos. La colonialidad de la arqueología se refleja en su propia conformación como empresa disciplinada de producción académica y en la medida en que genera discursividades como saberes expertos que conllevan la subalternización, negación y/o invisibilización de conocimientos "otros". Por ejemplo, a pesar de la existencia de leyes nacionales (artículo 75 inciso 17 de la Constitución Nacional 
Argentina y Ley 25.517/01 sobre restos mortales aborígenes), e internacionales (Convenio 169 de la OIT), de intenciones nacionales (Declaración de Río Cuarto) y de las cartas y recomendaciones de la UNESCO sobre participación de las comunidades locales en la toma de decisiones, gestión y administración del patrimonio, en la práctica la retórica multicultural sigue reproduciendo relaciones de poder-saber promoviendo construcciones conjuntas del conocimiento pero sin considerar las propias historias de esos "otros" (Gnecco 2005, McNiven y Russell 2005). De esa forma, la colonialidad de la arqueología deriva en diferentes estrategias de construcción del saber y que caracterizan a la ciencia moderna eurocéntrica tales como la separación entre hecho y valor, la "negación de la contemporaneidad" (sensu Fabian 1983), la primacía del objeto (ver Nastri 2004), la cosificación y la exterioridad y distancia en la definición de su objeto de estudio, proceso referido como la "ruptura metafísica" de la disciplina (sensu Haber 1999).

De esa manera, en la medida en que no podamos superar y abandonar los sentidos de colonialidad y eurocentrismo del conocimiento como principal modelo de ciencia, no será posible generar saberes "otros" y coproducidos sustentados en formas del conocer alternativas, situadas, plurales y transversales. Ello implica promover acciones que tiendan hacia la descolonización de nuestras prácticas y saberes disciplinarios (Haber 2006), y contribuyan a "expandir el presente" (sensu Santos 2006).

En este sentido, uno de los horizontes posibles de acción se encuentra en la interrelación entre epistemología y política como condición de posibilidad atenta a situaciones concretas y geopolíticas. Se trata de una puesta en obra a partir del descentramiento de la práctica disciplinaria, de formas distintas de promover la interacción y las expresiones de la pluriversalidad. Desde la filosofía de las ciencias sociales se han generado diferentes aproximaciones y/o formas del "hacer" que impactaron en las dimensiones teórico-prácticas y en las relaciones con los "otros" (Schuster 2002, Valdez 2004). Una de estas formas ha propuesto la producción de conocimientos desde el pluralismo cognitivo y visualizando al proceso de investigación como una práctica flexible de proliferación de teorías, métodos y valoraciones políticas y éticas (Feyerabend 1992, Facuse 2003). De esta manera, consideramos algunos aspectos conceptuales de la propuesta anterior que, sumados a una perspectiva de construcción del conocimiento en lugar (sensu Escobar 2005), conforman un ámbito de potencialidad para "expandir el presente" y promover prácticas decoloniales, críticas y situadas.

\section{Pluralismo cognitivo y el "todo vale"}

De acuerdo con Feyerabend (1992), el pluralismo cognitivo se constituye teniendo en cuenta dos dimensiones: la epistemológica y la ético-política. La primera, se relaciona con las formas en que se construye el conocimiento en el proceso de investigación. En este sentido, propone la proliferación de métodos, teorías, experiencias y la concurrencia de factores culturales, históricos y subjetivos. La segunda dimensión se relaciona con el ámbito éticopolítico en el cual establece una crítica acerca de las relaciones de saber/poder entre la ciencia y la sociedad y las formas en que se construye el conocimiento. La proliferación de los saberes plantea una nueva relación entre la ciencia y los otros campos del saber, remarcando la necesidad de abrir las fronteras de la misma, frente a otras tradiciones de conocimiento (e.g. saberes indígenas y/o locales). 
Por otro lado, el principio del "todo vale" no ha sido dimensionado en profundidad y por el contrario se ha considerado que el mismo sugiere que toda afirmación es válida de por sí, generándose una implicación literal de los conceptos originales. En su versión inglesa la expresión 'anything goes' es utilizada por Feyerabend en oposición a las epistemes ahistóricas y para reafirmar el sentido de las variantes propuestas de las contrareglas. No se trata de un principio que define un juicio final de valor como sostuvo y sostiene la crítica positivista, sino de puntos de partida múltiples, imprevistos y que desafían el componente normativo y unívoco del monismo metodológico. Es decir, en la investigación se debe tener en cuenta todo recurso metodológico que sea necesario y que es común y propio de toda ciencia (internalismo científico), como también considerar los hechos históricos, sociales y subjetivos que intervienen en la producción del conocimiento (externalismo científico). El 'todo vale' de Feyerabend implica prestar atención a las inconsistencias y las irregularidades que se dan en el proceso de investigación, como el surgimiento de situaciones, temas, actores e intereses no previstos, así como también fomentar la imaginación, la creatividad y asumir el procedimiento científico de una manera más flexible y móvil. La búsqueda del posicionamiento 'dadaísta' en la investigación intenta ser sobre todo una modalidad (en el sentido del hacer), una forma de abordar los problemas antes que un corpus cerrado y prescriptivo de normas y reglas específicas. Es decir, se trata de un planteo abierto y flexible para la construcción de un itinerario dinámico que cada investigador puede ajustar continuamente a las especificidades sociales y políticas del contexto cultural en el que se encuentra inserto (Facuse 2003). Con ello, Feyerabend se manifiesta expresamente en contra de la forma de concebir el desarrollo de la ciencia basado en el seguimiento estricto de las reglas del método planteadas por el racionalismo y el positivismo. Por el contrario, sostiene que a partir de la ruptura de las normas preestablecidas en el método científico será posible progresar en la construcción del conocimiento, ya que éste se enfrenta continuamente a situaciones complejas que no pueden circunscribirse a los estándares definidos a priori. Esto no implica que en la investigación no haya principios orientadores, sino que deben existir determinados criterios que son precisamente inherentes al propio proceso de construcción de los saberes y por lo tanto contingentes e históricamente situados. Es decir, cada investigación o cada campo de análisis tienen sus propios criterios de validación que serán definidos y redefinidos de acuerdo a las características específicas de cada proceso. Este posicionamiento es crítico de la visión de la ciencia como un cuerpo totalizante, universal y único de métodos, reglas fijas y procedimientos ahistóricos. En síntesis, a través de los conceptos de multiplicidad y pluralismo, Feyerabend propone la proliferación en un sentido epistemológico y de método, como también proliferación en relación a los saberes. El 'todo vale' se relaciona con un acercamiento pluralista para la construcción de los conocimientos (multiplicidad y proliferación de métodos), y también con las relaciones entre los distintos saberes y la tradición científica. El 'dadaísmo' epistemológico de Feyerabend se constituye simultáneamente en una crítica y en una propuesta abierta a través de la cual se busca que la ciencia tenga una función transformadora de la realidad social (función perdida en la concepción moderna de ciencia) y que defina un objetivo donde epistemología y política se comprendan en conjunto. Esta doble dimensión de la epistemología se define en lo metodológico con la manifestación de que no existen reglas definitivas y únicas que orientan la investigación, conjuntamente con la aceptación de otras visiones y elementos extracientíficos en la construcción del conocimiento y en el plano político con la crítica a la postura hegemónica, globalizante y excluyente de la ciencia moderna occidental. 


\section{Comentarios finales}

Anteriormente sosteníamos que la arqueología argentina se encuentra aún en la edad de la inocencia, sobre todo teniendo en cuenta las implicaciones sociales de la misma y las actitudes de desinvolucramiento y neutralidad que la caracterizan. Ese estado se debe, básicamente, a que la mayor parte de los casos siguen una agenda de investigación euronorteamericana cuyas formas del "hacer" se sustentan en postulados positivos y modernos. Según Quijano, esta perspectiva eurocéntrica del conocimiento, como principal modelo de ciencia, concentró bajo su hegemonía el control de todas las formas de subjetividad, de cultura y de producción de los saberes. En este sentido, la negación de los pueblos indígenas contemporáneos conformaba parte de la esencia de la cosmovisión moderna y del modus operandi instaurado a partir del imaginario colonial. Estas estrategias, conjuntamente con la elaboración de ideas racistas y etnocéntricas, constituyeron la base de los proyectos de construcción nacional hacia fines del siglo XIX en diferentes países sudamericanos en general y de Argentina en particular (Curtoni y Politis 2006).

La superación del eurocentrismo amerita, entre otras cosas, un anclaje de lugar en el sentido espacial, social, epistémico y político, es decir, una promoción de ámbitos y oportunidades localizados y concretos a partir de los cuales se generen puestas en escena de saberes otros y epistemologías otras. De esta forma, la conjunción de epistemología y política, atravesada por sentidos situados de las prácticas, conforma una alternativa de acción y promoción desde un locus de enunciación geopolítico específico. En ese contexto, la perspectiva decolonial promueve la puesta en obra, discusión y resignificación de saberes e ideas generados desde la diferencia colonial y apunta a las construcciones del conocimiento "en lugar" (Castro Gómez 2003, Dávalos 2005, Escobar 2005). Con el concepto decolonial se cuestiona el mito de la descolonización y la idea que la postmodernidad implica un mundo desvinculado de la colonialidad (Castro Gómez y Grosfoguel 2007). Por el contrario, el orden global contemporáneo resignifica las exclusiones provocadas por las jerarquías epistémicas, espirituales, étnicas y de género sostenidas y reproducidas por la modernidad. En otras palabras, se intenta co-promover y co-potenciar estrategias y espacios inclusivos, superadores del sentido de exclusividad académica, abriendo el juego a las acciones, interpretaciones y a los sentidos políticos de la práctica. Las implicaciones de ello se vinculan con el descentramiento académico, la insoslayable consulta y permiso de las comunidades locales, el entendimiento de la transversalidad del conocimiento, la consideración de las historias y saberes locales en sus propios términos, la puesta en escena de nuestros intereses, alcances y limitaciones, la búsqueda de consenso y visualización de las prácticas desde los ámbitos ético y político, el estar abiertos a construcciones conjuntas, coparticipadas y coproducidas. En definitiva, se trata de "abrir la arqueología" para simultáneamente "expandir el presente" y practicar una 'antropología de las ausencias' reconociendo un entorno más rico y fragmentado, de perspectivas encontradas e intereses en conflicto y conformado por saberes locales, alternativas del conocer, lenguajes y conceptos "otros" (Pálsson 2001, Santos 2006). Por ejemplo, el involucramiento y participación efectiva de los actores locales en la búsqueda y planteo de formas alternativas de manejo del patrimonio y sus historias implica la puesta en escena de discusiones y negociaciones para evaluar la pertinencia de las gestiones a realizar, para identificar lugares a ser significados y/o marcados, determinar las valoraciones asociadas, establecer y consensuar mecanismos de protección y promover construcciones del conocimiento localizadas. El desarrollo de estas alternativas integradoras, críticas y situadas se concibe como un espacio de oportunidad abierto, flexible y dinámico bajo las 
premisas de la transversalidad y pluriversalidad. De esa manera, el diálogo y el intercambio de opiniones contribuyen tanto al encuentro de saberes como de intereses en común fomentando las construcciones del conocimiento desde la diferencia y desde posicionamientos geopolíticos específicos.

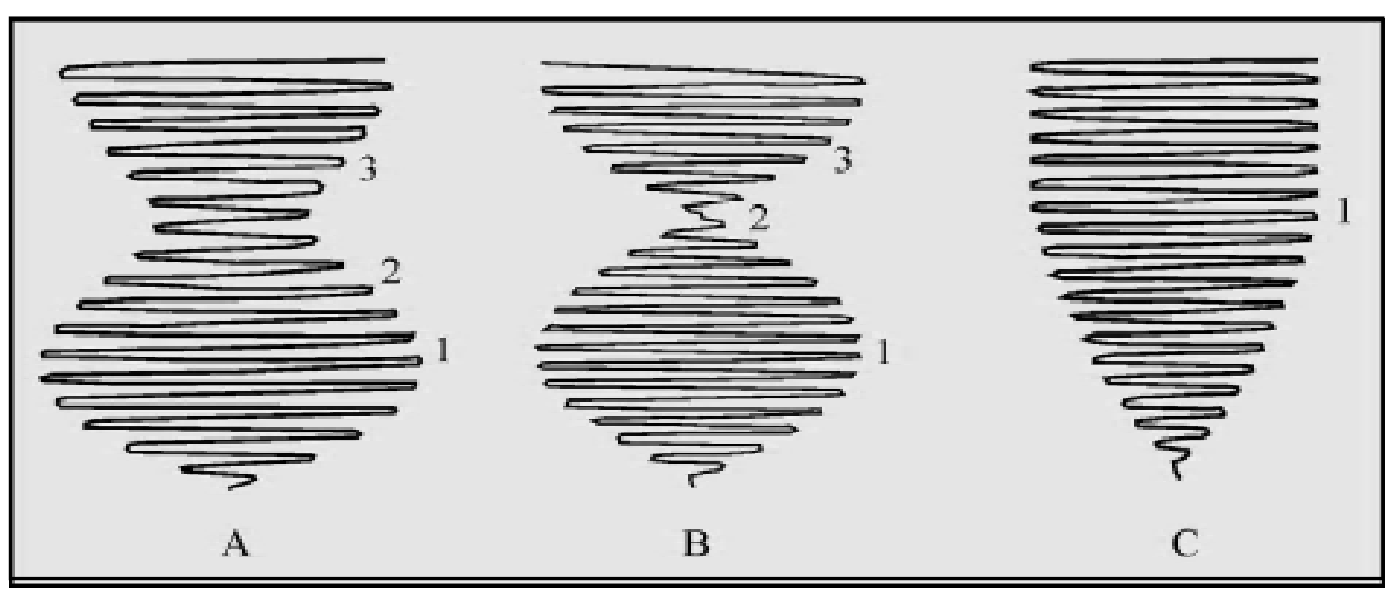

Figura 1. Modelos de Espirales Hermenéuticos

\section{Bibliografia}

Aschero, C., V. Ataliva, L. Cohen, S. López Campeny y C. Somonte 2003. Arqueología e identidad ... o identidad de la arqueología en la comunidad indígena de Amaicha del Valle (Tucumán, Argentina). Textos Antropológicos 15 (2): 263-276.

Ayala, P., S. Avendaño y U. Cárdenas

2003. Vinculaciones entre una arqueología social y la comunidad indígena de Ollagüe (Región de Antofagasta, Chile). Chungará 35 (2): 275-285.

Belli,E.y R.Slavutsky

2005a. Patrimonio: territorio, objetos, símbolos, personas. ¿Cuál es la disputa? Mundo de Antes 4:13-17.

Belli, E. y R. Slavutsky

2005b. Patrimonio en el Noroeste Argentino. Otras Historias. (eds. E. Belli y R. Slavutsky). Instituto Interdisciplinario Tilcara, Facultad de Filosofía y Letras, Universidad de Buenos Aires.

Berón, M. y M. Guastavino

2007. Manejo de recursos culturales y puesta en valor de historias regionales. IV Reunión Internacional de Teoría Arqueológica en América del Sur. Libro de Sesiones y Resúmenes, pp: 90. Universidad Nacional de Catamarca, Catamarca.

Biset, A.

1989. El Museo de Sitio de Añelo. Actas de las Jornadas del Uso del Pasado. Universidad Nacional de La Plata. 
Boaventura de Souza, S.

2006. Renovar la teoría crítica y reinventar la emancipación social. CLACSO Libros, Buenos Aires.

Callegari, A.

2007. Recursos culturales arqueológicos y turismo cultural en Villa Castelli (Oeste de la provincia de La Rioja). IV Reunión Internacional de Teoría Arqueológica en América del Sur. Libro de Sesiones y Resúmenes pp: 87-88. Universidad Nacional de Catamarca, Catamarca.

\section{Castro Gómez, S.}

2003. Ciencias Sociales, violencia epistémica y el problema de la invención del otro. La colonialidad del saber: eurocentrismo y ciencias sociales. Perspectivas latinoamericanas, (ed. por E. Lander), pp: 145-161. CLACSO, Buenos Aires.

Castro Gómez, S. y R. Grosfoguel

2007. El giro decolonial. Reflexiones para una diversidad epistémica más allá del capitalismo global. Siglo del Hombre editores, Bogotá, Colombia.

\section{Comerci, M. E.}

2004. Racionalidades, procesos productivos-reproductivos y estrategias de supervivencia en las familias del paraje pampeano de Chos Malal. Anuario 6: 27-39.

Cúneo, E.

2004. Huellas del pasado, miradas del presente: la construcción social del patrimonio arqueológico del Neuquén. Intersecciones 5: 81-94.

Curtoni, R. y M. L. Endere

2003. Teoría y práctica arqueológica en Sudamérica. Algunas reflexiones. En Análisis, Interpretación y Gestión en la Arqueología de Sudamérica (eds. R. Curtoni y M. L. Endere), pp. 715. INCUAPA, Olavarría.

Curtoni, R. y G. Politis

2006. Race and racism in South American archaeology. World Archaeology 38 (1): 93-108.

\section{Curtoni, R. y M. G. Chaparro}

2007. El espejo de la naturaleza y la enfermedad histórica en la construcción del conocimiento. Intersecciones en Antropología 9, en prensa.

Curtoni, R., M. G. Chaparro, R. Dargoltz, N. Velliz, N. Mendoza, C. Salomón, M. E. Comerci y L. Valencia

2007. 'No hay hombres sin tierras ni tierras sin hombres'. El nuevo despojo de los campesinos santiagueños y pampeanos. IV Reunión Internacional de Teoría Arqueológica en América del Sur. Libro de Sesiones y Resúmenes pp: 96. Universidad Nacional de Catamarca, Catamarca.

Dargoltz, R.

1980. Hacha y Quebracho. Historia ecológica y social de Santiago del Estero. Ediciones Castañeda, Buenos Aires.

Dargoltz, R., O. Gerez, H. Cao y J. Vaca (editores)

2005. Santiago. El ala que brota. Editorial Utopía y Sueños, Buenos Aires. 
Dávalos, P.

2005. Movimientos indígenas en América Latina: el derecho a la palabra. En Pueblos Indígenas, Estado y Democracia, (ed. por P. Dávalos), pp: 17-33. CLACSO, Buenos Aires.

Declaración de Río Cuarto 2005. Primer Foro Pueblos Originarios - Arqueólogos. Río Cuarto, Argentina. Comentarios. Revista de Arqueología Suramericana 1(2): 287-293.

Delfino, D. y P. Rodríguez

1992. La recreación del pasado y la invención del patrimonio arqueológico. Publicar - En Antropología y Ciencias Sociales 2: 29-68.

Delfino, D., A. Barale, V. Espiro y R. Díaz

2006. Los viejos nuevos desafíos de la Arqueología argentina. Problemas y resultados de la práctica arqueológica con la comunidad de Laguna Blanca. Libro de Resúmenes del VIII CAAS, pp. ,91-92, Salta.

\section{Diario Río Negro}

2005. "Denuncian profanación de un cementerio mapuche", 23 de mayo. Versión digital: http://rionegro.com.ar/arch200505/23/v23s06.php.

\section{Diario Río Negro}

2006. "Se incendió una casilla de la ocupación mapuche", 17 de julio. Versión digital: http:/ /rionegro.com.ar/diario/2006/07/17/20067117f05.php.

Endere, M.L.

2002. Management of archaeological sites and the public in Argentina. Tesis doctoral inédita. Institute of Archaeology, University College of London.

Endere, M. L.

2005. Discusión. Patrimonio: territorio, objetos, símbolos, personas. ¿Cuál es la disputa? de Belli, E. y R. Slavutsky, Mundo de Antes 4: 18-20.

Endere, M. L. y R. Curtoni

2003. Patrimonio, arqueología y participación: acerca de la noción de paisaje arqueológico. En Análisis, Interpretación y Gestión en la Arqueología de Sudamérica (eds. R. Curtoni y M. L. Endere), pp. 277-296. INCUAPA, Olavarría.

Endere, M. L. y R. Curtoni

2006. Entre lonkos y "ólogos". La participación de la comunidad indígena Rankülche de Argentina en la investigación arqueológica. Arqueología Suramericana 2 (1): 72-92.

Escobar, A.

2005. Más allá del tercer mundo. Globalización y diferencia. Instituto Colombiano de Antropología e Historia, Bogotá. 
Facuse, $\mathrm{M}$.

2003. Una epistemología pluralista. El anarquismo de la ciencia de Paul Feyerabend. Cinta de Moebio Nro. 17, Facultad de Ciencias Sociales. Universidad de Chile http:// www.moebio.uchile.c1/17/frames02.htm.

Feyerabend, $\mathrm{P}$.

1992. Tratado contra el método. Esquema de una teoría anarquista del conocimiento. Editorial Tecnos, Madrid.

Font, L., E. Cúneo, E. Billinger y N. Muelas

1997. El Museo y la Escuela. Algunos aportes sobre la base de la experiencia desarrollada en la provincia de Neuquén. Ponencia presentada VII Encuentro Educativo El Museo y La Escuela. Archivo y Museo Histórico Dr. Jauretche, Buenos Aires.

Foucault, M.

1997. La arqueología del saber. Siglo XXI Editores, México.

Funari, P. y A. Zarankin (ed.)

2006. Arqueología de la represión y la resistencia en América Latina 1960-1980. Editorial Brujas, Córdoba.

Gnecco, C.

2005. Ampliación del campo de batalla. Simposio Pueblos Originarios y Arqueología (Memorias). Textos Antropológicos 15(2): 183-195.

Gnecco, C. y C. Piazzini (ed.)

2003. Arqueología al desnudo. Reflexiones sobre la práctica disciplinaria. Editorial Universidad del Cauca, Popayán, Colombia.

Gómez Otero, J., J. Moreno, G. Cladera, S. Dahinten, R. Taylor y H. Pallares

2007. Minería, pueblos originarios y arqueólogos: una experiencia de trabajo en la provincia de Chubut (Patagonia Argentina). IV Reunión Internacional de Teoría Arqueológica en América del Sur. Libro de Sesiones y Resúmenes pp: 125-126. Universidad Nacional de Catamarca, Catamarca.

Granizo, G.

2007. Límites y posibilidades del turismo cultural como factor de desarrollo local. IV Reunión Internacional de Teoría Arqueológica en América del Sur. Libro de Sesiones y Resúmenes, pp: 91. UNCat. Catamarca.

Green, L., D. Green y E. Neves

2003. Indigenous knowledge and archaeological science: The challenges of public archaeology in the Reserva Uaçá. Journal of Social Archaeology, Vol. 3 (2) pp. 366-397.

Haber, A.

1999. Caspinchango, la ruptura metafísica y la cuestión colonial en la arqueología Sudamericana: el caso del noroeste argentino. Revista Do Museu de Arqueologia e Etnologia Suplemento 3: 129-141. San Pablo, Brasil. 
Haber, A.

2005. Discusión. Patrimonio: territorio, objetos, símbolos, personas. ¿Cuál es la disputa? de Belli, E. y R. Slavutsky, Mundo de Antes 4: 21-22.

Haber, A.

2006. Verdad o consecuencia. En Problemáticas de la Arqueología Contemporánea. Publicación del XV Congreso Nacional de Arqueología Argentina, A. Austral y M. Tamagnini (comp.), pp. 331-334. Universidad Nacional de Río Cuarto, Río Cuarto.

Haber, A., J. Ramos, L. D’Amore, C. Lema, W. Londoño, E. Moreno y M. Quesada 2006. Hacer arqueología, hacer comunidad: 17 años en Antofalla. Libro de Resúmenes VIII Congreso Argentino de Antropología Social, pp. 93. Universidad Nacional de Salta, Salta.

Iriarte, C. y P. Werber

2003. Participación comunitaria y patrimonio en la localidad de Puelches (Pcia. de La Pampa), hacia el desarrollo social y económico. Presentado en las Primeras Jornadas Nacionales de Transferencia Universitaria, Facultad de Filosofía y Letras, UBA.

Laguens, A. y M. Bonnin

1985. Hacia una arqueología aplicada. El programa de estudios arqueológicos del departamento San Carlos, Valle Calchaquí Sur, Pcia. de Salta, Argentina. Aspectos teóricos y de método. Publicaciones XL, Instituto de Antropología, Universidad Nacional de Córdoba, pp. 29-65. Córdoba.

Lema, C.

2007. De 'avaricia' y 'celosía'. Tensiones y conflictos por la explotación minera en la Puna de Atacama. IV Reunión Internacional de Teoría Arqueológica en América del Sur. Libro de Sesiones y Resúmenes pp: 97. Universidad Nacional de Catamarca, Catamarca.

Lima, P.

2003. Participación comunitaria, desarrollo sostenible y arqueología: el caso Quila Quila (Chuquisaca, Bolivia). Chungará 35 (2): 361-365.

Mamaní, H. E.

2006. Consulta, diálogo, respeto y participación comunitaria en la gestión del patrimonio arqueológico. Libro de Resúmenes VIII Congreso Argentino de Antropología Social, pp. 94. Universidad Nacional de Salta, Salta.

Marchegiani, M., V. Palamarczuk, G. Pratolongo y A. Reynoso

2006. Nunca serán ruinas: visiones y prácticas en torno al antiguo poblado de Quilmes en Yocavil. En Problemáticas de la Arqueología Contemporánea. Publicación del XV Congreso Nacional de Arqueología Argentina, A. Austral y M. Tamagnini (comp.), pp. 313-323. U. N. de Río Cuarto, Río Cuarto.

Miotti, L. y N. Carden

2006. Rumbo a la nada. La experiencia en la práctica arqueológica desde un lugar de Patagonia. En Problemáticas de la Arqueología Contemporánea. Publicación del XV Congreso Nacional de Arqueología Argentina, A. Austral y M. Tamagnini (comp.), pp. 309-311. Universidad Nacional de Río Cuarto, Río Cuarto. 
McNiven, I. y L. Russell

2005. Appropriated Pasts. Indigenous peoples and the Colonial culture of Archaeology. A Division of Rowman y Littlefield Publishers, Inc., Oxford.

Molinari, R.

2000. ¿Posesión o participación? El caso del Rewe de la comunidad Mapuche Norquinco (Parque Nacional Lanín, Provincia de Neuquén, Argentina). Segundo Congreso Virtual de Antropología y Arqueología. Facultad de Fililosofía y Letras, UBA.Website:http:// www.naya.org.ar/congreso.htm.

Montenegro, M. y B. Cremonte

2007. Patrimonio arqueológico e interculturalidad en el sur de la Quebrada de Humahuaca (Jujuy). IV Reunión Internacional de Teoría Arqueológica en América del Sur. Libro de Sesiones y Resúmenes, pp: 89. Universidad Nacional de Catamarca, Catamarca.

Nielsen, A., J. Calcina y B. Quispe

2003. Arqueología, turismo y comunidades originarias: una experiencia en Nor Lípez (Potosí, Bolivia). Chungará 35 (2): 369-377.

Palma, J., S. Fernández Do Río, M. Runcio y L. Capizzi

2007. Museo arqueológico e histórico de Huacalera (Quebrada de Humahuaca, provincia de Jujuy): un trabajo junto a la comunidad. Intersecciones en Antropología 8: 163-171.

Pálsson, G.

2001. Relaciones humano-ambientales. Orientalismo, paternalismo y comunalismo. Naturaleza y Sociedad. Perspectivas antropológicas, (P. Descola y G. Pálsson eds.), pp. 80-100. Siglo XXI, México.

Politis, G.

2001. On archaeological praxis, gender bias and indigenous peoples in South America. Journal of Social Archaeology 1 (1): 90-107.

Revuelta, C.

2007. El paisaje acechado. Resistencias locales y patrimonio arqueológico frente a la minería a gran escala. perspectiva desde la Sierra del Famatina (La Rioja). IV Reunión Internacional de Teoría Arqueológica en América del Sur. Libro de Sesiones y Resúmenes pp: 122. Universidad Nacional de Catamarca, Catamarca.

Seldes, V., J. Cabral, J. Rodríguez, L. Yazlle y M. Zigarán

2006. Arqueología y Turismo en los Valles Calchaquíes: la historia de Cachi a través de sus pobladores. Libro de Resúmenes VIII Congreso Argentino de Antropología Social, pp. 96. Universidad Nacional de Salta, Salta.

Schuster, F (compilador).

2002. Filosofía y Métodos de las Ciencias Sociales. Editorial Manantial, Bs As. 
Torterolo, $\mathrm{M}$.

2005. La expansión de la frontera agrícola, un acercamiento desde el punto de vista climático. Apuntes Agroeconómicos 4(3). Facultad de Agronomía. UBA. ISSN 1667-3212. Versión digital: http://www.agro.uba.ar/apuntes.

Valdez, L.

2004. La filosofía de la arqueología de América Latina. En Teoría Arqueológica en América del Sur, G. Politis y R. Peretti (eds), pp. 129-140. Facultad de Ciencias Sociales, Olavarría.

Vattimo, G.

1989. La sociedad transparente. Ediciones Paidós Ibérica S.A., Barcelona.

Vitry, C. y S. Soria

2006. Arqueólogos y comunidades en busca del pasado. Libro de Resúmenes VIII Congreso Argentino de Antropología Social, pp. 93. Universidad Nacional de Salta.

Zaburlin, M. A., V. Seldes y P. Mercolli

2006. Reflexiones sobre los últimos rescates arqueológicos en Tilcara. En Problemáticas de la Arqueología Contemporánea. Publicación del XV Congreso Nacional de Arqueología Argentina, A. Austral y M. Tamagnini (comp.), pp. 325-326. Universidad Nacional de Río Cuarto, Río Cuarto. 